\title{
EFFECT OF PEPTIDE HORMONES ON SEXUAL MOTIVATION IN RATS AFTER CHRONIC SOCIAL ISOLATION
}

\author{
I.Y. Tissen, L.A. Magarramova, A.A. Lebedev and P.D. Shabanov \\ Department of Neuropharmacology, Institute of Experimental Medicine, \\ 197376, Russia, St. Petersburg, Akad. Pavlov st., 12.
}

DOI: 10.19163/MedChemRussia2021-2021-285

E-mail: iljatis@mail.ru

Social isolation in early life deregulates reproductive function. It is known that kisspeptin stimulates secretion of gonadotrophin releasing hormone. The aim of this study was to examine the effects of social isolation and some hormonal peptides on sexual motivation in male rats. Wistar males $(n=60)$ were used, into 6 groups. Animals in the first group were intact. In the other groups, the rats were housed in full social isolation since the $17^{\text {th }}$ up to 100 days. Control animals were administrated with saline while the remaining groups were administrated with Buserelin acetate 40 $\mu \mathrm{g}$ intranasally, Kisspeptin-10 $3 \mu \mathrm{g}$ intranasally, Kisspeptin-10 30 $\mu \mathrm{g} / \mu \mathrm{l}$ intraperitoneally.

Open-field reward-proximity chamber was used for assessment of sexual motivation. The chamber construction allowed the subjects to investigate estrous female but prevented copulation. Behavior was registrated in the dark room with red light for 10 minutes. Blood samples for testosterone ELISA were collected at 30 min after substance administration from tail vein.

Social isolation didn't significantly act on latent time before trying to reach the female $(11,2 \pm 9,6 \mathrm{sec}$.vs $8,0 \pm 4,5 \mathrm{sec}$. in control). Only intranasal administration of kisspeptin-10 reduced latent time $(5,3 \pm 1,7 \mathrm{sec})$. Both Kisspeptin-10 forms induced trying to reach the female $(17,5 \pm 3,5$ Kiss- $10 \mathrm{I} / \mathrm{N}, 19,3 \pm 3,9 \mathrm{Kiss}-10 \mathrm{I} / \mathrm{P}$ vs $13,8 \pm 3,1$ in control). Social isolation decrease testosterone level twice $(7,5 \pm 2,9$ $\mathrm{nmol} / \mathrm{ml}$ vs $14,5 \pm 6,2 \mathrm{nmol} / \mathrm{ml}$ in control). Buserelin acetate and intraperitoneal but not intranasal kisspeptin-10 restore testosterone level about control $(19,5 \pm 4,3 \mathrm{nmol} / \mathrm{ml}$ and $13,6 \pm 4,2 \mathrm{nmol} / \mathrm{ml})$.

These data show that the effect of social isolation affects hormonal status more than sexual motivation per se. This provides the preconditions for finding new mechanisms underlying the regulation of reproductive behavior and the effect of stress factors on its realization.

\section{References}

[1] E.G.A. Mills, K.T. O’Byrne, A.N. Comninos Kisspeptin as a Behavioral Hormone. 2019 Semin. Reprod. Med.;37(2):56-63.

[2] S.B.Z.Stephens, A.S. Kauffman Regulation and Possible Functions of Kisspeptin in the Medial Amygdala. 2017 Front Endocrinol (Lausanne).; 8: 191.

[3] I.Y. Tissen, L.A. Magarramova, A.S. Kraskova, P.P. Khokhlov, A.A. Lebedev, P.D. Shabanov Kisspeptin and gonadotropin releasing hormone independently regulated sexual motivation in male rats. 2019 Steroids. and nervous system con. Mat.; 204-205. 